\title{
Drawing Attention to Global Climate Change Decreases Support for War
}

\author{
Tom Pyszczynski \\ University of Colorado at Colorado Springs
}

\author{
Kenneth E. Vail, III \\ University of Missouri
}

\author{
Jamie Arndt \\ University of Missouri
}

\author{
Matt Motyl \\ University of Virginia
}

\author{
Pelin Kesebir \\ University of Colorado at Colorado Springs
}

\begin{abstract}
Three studies showed that focus on the shared human threat of global climate change can encourage peaceful coexistence and discourage support for war in the face of existential threat. In Study 1, mortality salience (MS) increased Americans' support for international peace-building after imagining the consequences of global climate change, but not after imagining a localized catastrophe. Conversely, in Study 2, MS increased Americans' support for war against Iran after imagining a localized catastrophe, but imagining global climate change completely eliminated this effect. Study 3 was conducted among Arab citizens of Israel during the January 2009 Israeli invasion of Gaza. For those high in perceptions of shared humanity, MS increased support for peaceful coexistence with Israeli Jews after imagining global climate change but not a localized catastrophe that would affect both Muslims and Jews. Taken together, these studies suggest that reminders of global climate change short-circuit the increased support for violence that often occurs in response to existential threat and increase support for peaceful reconciliation.
\end{abstract}

Keywords: global climate change, terror management theory, existential anxiety, peace psychology, intergroup conflict, intergroup violence

TOM PYSZCZYNSKI is Distinguished Professor of Psychology at the University of Colorado at Colorado Springs. His research is concerned with the role of existential concerns in human behavior, recently with particular focus on intergroup conflict, war, terrorism, and morality.

Matт Motyl is a Doctoral Candidate in Social Psychology at the University of Virginia. His research focuses on understanding and ameliorating intergroup conflicts when sacred values are at stake. He is also Co-Director of CivilPolitics.org, a nonprofit academic website that brings together research and scholars from many disciplines to try to foster improved communication between groups in conflict.

Kenneth E. VAIL, III is a PhD student at the University of Missouri who received his M.A. in 2010, and his BA from the University of Colorado at Colorado Springs in 2008. His research has focused on such questions as how peoples' management of existential concerns influences geopolitical affairs, religion, and motivations for authenticity and self-determination.
GILAD HIRSCHBERGER is associate professor of psychology at the Interdisciplinary Center (IDC) Herzliya, Israel. His main research interests are interpersonal and intergroup conflict, prosocial motivation, and terror management theory.

JAMIE ARNDT received his PhD from the University of Arizona in 1999 and is the Frederick A. Middlebush Professor of Psychological Sciences at the University of Missouri. His research explores motivational and existential dynamics of the human condition, and how these interface with various forms of social and health behavior.

Pelin KesebiR is a post-doctoral researcher at the University of Colorado, Colorado Springs. Her research explores different aspects of existential motivation.

CORRESPONDENCE CONCERNING THIS ARTICLE should be addressed to Tom Pyszczynski, University of Colorado at Colorado Springs, Department of Psychology, 1420 Austin Bluffs Parkway, Colorado Springs, CO 80918. E-mail: tpyszczy@uccs.edu 
One of the few gratifying and exalting impressions which mankind can offer is when, in the face of an elemental catastrophe, it forgets the discordancies of its civilization and all its internal difficulties and animosities, and recalls the great common task of preserving itself against the superior power of nature.

—Sigmund Freud, The Future of an Illusion (1927, p. 16)

Today's world remains locked in violent conflicts while facing a multitude of other problems, such as economic recession and global climate change. How might these different types of challenges influence one another? On the one hand, climatic disruption could exacerbate the many other problems humankind is facing and lead to increased competition for resources and intensified international conflict (Anderson \& DeLisi, 2011). On the other hand, widespread acknowledgment of the shared global consequences of environmental degradation before disaster strikes might tap into psychological processes that could help mitigate conflict. Cognizance of the shared global consequences of climate change could create a sense of shared threat that implies that diverse groups of humans, even those currently in conflict with each other, must work together to avoid an impending catastrophe. In this article, we combine ideas from terror management theory (TMT; Greenberg, Pyszczynski, \& Solomon, 1986; Kesebir \& Pyszczynski, 2012; Pyszczynski, Solomon, \& Greenberg, 2003) with findings from classic social psychological research showing that a shared threat can promote cooperation among competing groups (e.g., Sherif, 1966) to explore one set of conditions under which drawing attention to the threat of global climate change might encourage international cooperation and discourage international conflict.

\section{TMT}

TMT research has documented the conflictenhancing effect of existential threat in international disputes by showing that reminders of death often increase support for war and terrorism (e.g., Hirschberger \& Ein-Dor, 2006; Pyszczynski et al., 2006). However, recent research has shown that increased intergroup conflict is not an inevitable consequence of existential threat and that activating cultural values that promote compassion and a sense of shared humanity can reduce and even reverse the effect of existential threat on support for war (for a review, see Motyl, Vail, \& Pyszczynski, 2009). These findings are compatible with earlier TMT studies showing that priming values such as tolerance or pacifism can prevent mortality salience (MS) from leading to prejudice and aggression toward the outgroup, and lead to more tolerant and pacifistic attitudes (e.g., Greenberg, Simon, Pyszczynski, Solomon, \& Chatel, 1992; Jonas et al., 2008). The research reported here tested the hypothesis that drawing attention to the potential shared catastrophic effects of global climate change could reduce or even reverse the effect of existential threat on support for violence.

TMT posits that human awareness of the inevitability of death creates the potential for existential terror, which is both highly aversive and capable of undermining adaptive behavior unless effectively managed. According to the theory, people stave off this potential for anxiety by: (a) maintaining faith in cultural worldviews that imbue life with meaning, value, and permanence, (b) garnering self-esteem, by living up to their culture's standards of value, and (c) maintaining close interpersonal attachments. This protection is threatened by those who hold worldviews different from one's own and those who derogate one's group; this undermines the faith in these anxiety-buffering conceptions that is required for effective functioning.

From the perspective of TMT, intergroup conflict is thus motivated, in part, by threats to one's worldview and self-esteem posed by the beliefs, values, and behavior of outgroup members. People support discrimination, hostility, and violence against those who threaten their anxiety-buffering conceptions of world and self (Pyszczynski et al., 2003). Accordingly, reminders of death increase hostility toward groups with worldviews different from one's own, especially when these groups are perceived to violate cherished moral values (Kesebir \& Pyszczynski, 2011). Research has shown that reminders of mortality can encourage aggression toward political outgroup members (McGregor et al., 1998), sectarian strife (Greenberg et al., 1990), and prejudice toward other nations (Castano, Yzerbyt, Paladino, \& Sacchi, 2002; for a review, see Castano \& Dechesne, 2005). MS also has been shown to increase support for war and the use of military might among Americans and Israelis, and support for 
martyrdom missions to kill Americans among Iranians (Hirschberger \& Ein-Dor, 2006; Pyszczynski et al., 2006).

However, TMT does not imply that people always respond to existential threat by lashing out at those who threaten their worldviews. Rather, the theory suggests that people use whatever aspect of their worldview is most likely to provide security in the particular situation they find themselves. Research supports this malleability of terror management defenses. For example, reminding religious fundamentalists of the compassionate teachings of their religions (Rothschild, Abdollahi, \& Pyszczynski, 2009), activating thoughts of warm and caring interactions with attachment figures (Weise et al., 2008), presenting violence as subhuman and animalistic (Motyl, Hart, \& Pyszczynski, 2010), highlighting personal susceptibility to harm, or nonviolent adversary intents (Hirschberger, Pyszczynski, \& Ein-Dor, 2009) redirects responses to MS away from support for political violence. Thus, although MS often increases hostility toward outgroups as a way of fending off the threat they pose to one's own worldview, it also encourages people to strive for selfesteem by living up to salient standards of their worldviews. Thus, when beliefs and values antithetical to violence are salient, MS would be expected to decrease support for violent resolutions to conflicts.

\section{The Impact of Superordinate Goals, Identities, and Threats}

Sherif's classic Robbers Cave experiments illustrated that arbitrary group divisions can cultivate intergroup antagonism, but simultaneously showed that conflict can be ameliorated when superordinate goals require the cooperation of formerly competing groups (Sherif, Harvey, White, Hood, \& Sherif, 1961). Allport (1954) suggested that viewing "humanity" as the ultimate ingroup category could encourage peaceful coexistence. More recently, the Common Ingroup Identity Model (CIIM; Gaertner, Dovidio, Anastasio, Bachman, \& Rust, 1993) suggested that reframing subordinate groups as a single superordinate inclusive group can reduce hostility. Consistent with the CIIM, research has shown that when subordinate groups are led to contemplate shared aspects of their social identities, they cease to display inter- group bias (Gaertner \& Dovidio, 2000; also see Gaertner, Mann, Murell, \& Dovidio, 1989; Houlette et al., 2004; Nier et al., 2001).

Most of the research conducted in these traditions, however, examines relations between artificial groups created in the laboratory or faced with somewhat artificial superordinate goals, and none have assessed these processes within the context of long-standing real world intractable conflicts. For example, some of this research examined relations between ad hoc minimal groups by having participants sit in different colored chairs or in different spatial configurations in the laboratory (e.g., Gaertner et al., 1989). Shared superordinate goals and group identities in this research are often similarly artificial in nature. For example, Gaertner et al. (1999) induced superordinate goals for participants in different subgroups by offering each individual a small $\$ 10$ award for cooperating with the other groups to devise the best resolution to an artificial budget deficit. Mottola, Bachman, Gaertner, and Dovidio (1997) induced superordinate group identification by having undergraduate students role-play as employees of corporations that are merging together (as opposed to one absorbing the other).

To our knowledge, the research reported here is among the first to assess the effect of focusing attention on a very serious shared global threat - climate change-on support for war and peace-making among parties to volatile ongoing real world conflicts, specifically the conflicts between the US and Iran and between the Palestinians and Israelis. Although some previous studies considered the relationship between global climate change and war, for example using historical data to show that long-term climate change has driven past wars (Zhang, Brecke, Lee, He, \& Zhang, 2007), our study takes an experimental approach, and investigates processes through which awareness of global climate change might encourage peace rather than war.

Sherif (1966) posited that, much like a superordinate goal or group identity, the presence of a shared threat can encourage intergroup cooperation and reduce conflict. An early study found, for example, that participants awaiting a painful electric shock were more likely to help someone they thought was sharing the same threat, but not someone who was not (Darley \& Morris, 1975). Others demonstrated that per- 
ceived interdependence born from a shared threat plays a key role in the formation of ingroup/outgroup boundaries (Flippen, Hornstein, Siegal, \& Weitzman, 1996). Presumably, shared fate and shared threat lead to a recategorization of group boundaries and give rise to a sense of "we-ness," which in turn increases intergroup cooperation and reduces intergroup conflict. Unfortunately, relatively few studies have documented the conflict-assuaging properties of shared threat and, to our knowledge, no research has yet examined the interplay between shared threats and variables such as MS, that have been shown to exacerbate support for violence among groups with long histories of intractable conflict.

The present studies were designed to integrate previous work on shared group identity and shared threat with TMT ideas about the existential roots of intergroup conflict. We sought to determine if focus on a shared global threat-specifically, the threat of global climate change-can reduce or reverse the common finding that existential threat exacerbates intergroup conflicts. Given the increasingly globalized nature of the modern world, and the need for diverse groups with sometimes opposing interests to work together to remedy these problems, it is important to know if heightening awareness of the shared nature of these threats might help reduce the costly conflicts that embroil much of the world today.

\section{Global Climate Change as Superordinate Threat}

The vast majority of the scientific community agrees that the earth's climate is changing, that these changes have the potential to produce catastrophic consequences, and that humans have been contributing to this phenomenon (e. g., Canadian Meteorological \& Oceanographic Society, 2002; Joint Science Academies, 2005). Although the severity of the predicted effects of climate change are disputed by some (Ball, 2007), many scientists have warned of the potential for cataclysmic global disasters, including extinction of animal species, flooding of densely populated coastal areas, forced evacuations and migrations in regions no longer able to support agriculture, disruptions of weather patterns, drought, famine, and increased competition for resources (Hileman, 1999; Intergovern- mental Panel on Climate Change [IPCC], 1996; Schneider, 1997).

Building on research from psychology, sociology, political science, economics, history, and geography, Anderson and DeLisi (2011) present evidence that global climate change might intensify existing intergroup conflicts and create new ones. Both experimental and correlational studies establish that uncomfortably warm temperatures increase physical aggression and violence (e.g., Anderson \& Anderson, 1998; Anderson, Anderson, Dorr, DeNeve, \& Flanagan, 2000). In addition to the direct effects of global climate change on irritability and aggression, there would likely also be indirect effects on populations whose livelihoods and survival are threatened by the changes brought about by global climate change. As realistic group conflict theory (Sherif et al., 1961) suggests, the inevitable decrease in resources precipitated by global climate change could lead to more intergroup violence as groups try to secure the resources they need. In fact, some argue that climate change already has exacerbated existing tensions and conflicts in the Darfur region of Sudan and in Bangladesh (Anderson \& DeLisi, 2011).

Although the potential for global catastrophe, including increased intergroup conflict, is great if the projected effects of global climate change occur, research and theory (Allport, 1954; Gaertner et al., 1993) suggest another possibility, at least before these consequences become too severe. Awareness of the shared nature of this impending threat could encourage cooperation among those affected and might even facilitate resolution of long-standing conflicts. This article presents three studies examining the interactive effect of existential threat and contemplating the consequences of global climate change. Based on TMT and classic theories and research on the impact of shared goals and threats, we hypothesized that reminders of death would lead people focusing on the shared global consequences of climate change to increase their support for peace and reconciliation and decrease their support for war.

\section{Study 1}

Although thoughts of death frequently fuel hostility toward outgroups (Motyl et al., 2009), a global threat such as climate change may 
induce a sense of shared fate and therefore activate the goal of cooperation and peacemaking. If that is the case, support for peacebuilding in response to thoughts of global climate change should be increased by MS. To test this hypothesis, we asked participants to imagine the global consequences of climate change. Our dependent measure in Study 1 was support for structural peace-building, which refers to the proactive healing and prevention of violent conflict through the institutional elimination of social injustice and violent conflict (Christie, Tint, Wagner, \& Winter, 2008). To control for the effects of imagining a catastrophe and to emphasize the impact of a shared global disaster, control participants were asked to think about a catastrophic event that affects only people in a specific region, in this case, a major earthquake in San Francisco. We hypothesized that focusing on global climate change, which is a threat to all humanity, would boost support for international peace-building, especially under conditions of MS.

\section{Method}

Participants. One hundred and nine psychology students (61 women, 48 men) at a Rocky Mountain region university in the United States participated in return for course credit. ${ }^{1}$ Participants ranged in age from 18 to 47 years $(M=21.85, S D=4.80)$.

Materials and procedure. The study was conducted in small groups. Participants completed a series of filler questionnaires prior to exposure to experimental manipulations. Next, they completed one of two versions of a catastrophe imagination exercise. Each introduced a threat followed by a list of possible effects for participants to consider. In the global climate change condition, participants were asked to imagine, regardless of their beliefs of the likelihood of such events, the global consequences of climate change such as: melting ice caps and rising sea-levels; forced migrations and evacuations; rising temperatures and severe storms; long drought seasons; and shifts in energy sources. In the localized catastrophe condition, participants were asked to imagine, regardless of their beliefs of the likelihood of such an event, an earthquake in San Francisco, the much-feared "big one," and its local consequences such as: disturbing the San Francisco Bay; forcing San Franciscans to relocate; damaging the city and local crops; and reconstruction efforts throughout the region. Pilot testing revealed that even participants who do not believe climate change to be a real threat write about possible worldwide problems attributable to climate change when instructed to put aside their personal beliefs about the likelihood of such events happening, as instructed to do so in these studies.

Participants then completed two questions related to either death or dental pain, an aversive control topic. Specifically, participants were asked to: "Please briefly describe the emotions that the thought of death [dental pain] arouses in you," and "Jot down, as specifically as you can what you think will happen to you as you physically die [experience dental pain] and once you have physically died [experienced dental pain]." Next, participants completed a distraction task (brief word search puzzle) meant to facilitate thoughts of death fading from conscious attention. Such fading from focal attention is essential for instigating worldview defense because distal terror management defenses are activated when thoughts of death are highly accessible but not in focal attention (Pyszczynski, Greenberg, \& Solomon, 1999).

A 14-item version of the Support for Diplomacy Scale (SDS; Vail \& Motyl, 2010), designed to assess structural peace-building attitudes, was the dependent measure. Each SDS item was measured on an 11-point scale $(11=$ strongly agree, $1=$ strongly disagree). The measure included statements such as, "Leaders of the United States should actively engage in diplomatic efforts with the leaders of states who sponsor terrorism (e.g., Iran, Libya, Syria)" and "America's strong military showing undermines its peaceful goals." The SDS demonstrated excellent internal reliability (Cronbach's alpha $=.91$ ). After completing the SDS, participants were thanked for their participation, probed for suspicion, given course credit, and debriefed.

\section{Results and Discussion}

A 2 (MS: Death vs. Dental Pain) $\times 2$ (Catastrophe: Global Climate Change vs. San Francisco Earthquake) analysis of variance (ANOVA) on support for peace-building re-

\footnotetext{
${ }^{1}$ Seven participants were excluded from subsequent analyses because they skipped over the open-ended manipulation questions that were crucial to the study.
} 
vealed only the predicted MS $\times$ Climate Change interaction, $F(1,105)=4.66, p<.05, \eta^{2}=.04$. Tests for simple main effects revealed that MS had no effect on peace-building among participants primed with a localized catastrophe, $F(1$, $105)=0.38, n s$. However, in the global climate change condition, MS increased support for peace-building, $F(1,105)=5.82, p<.05, \eta^{2}=$ .05 (Figure 1). Looked at differently, within the pain condition, there was a nonsignificant trend toward an effect of the threat manipulations, $F(1,105)=2.45, p=.12$. Among participants in the pain condition, those primed with the global common catastrophe $(M=7.07, S D=$ 2.11) tended to be less supportive of peacemaking than those primed with the local uncommon catastrophe $(M=7.80, S D=1.63)$. A nonsignificant trend in the opposite direction was found within the death condition, $F(1,105)=$ $2.21, p=.14$. Among participants in the death condition, those primed with the global common catastrophe $(M=8.19, S D=1.42)$ were marginally more supportive of peacemaking than those primed with the local uncommon catastrophe $(M=7.52, S D=1.51)$. These findings provide further evidence that existential threat does not always increase intergroup conflict-thoughts of death encouraged support for peace-building when participants were focused on the potential shared catastrophic consequences of global climate change.

Although MS tended to decrease support for peace building in the control condition, this effect was not statistically significant. This weak trend may appear inconsistent with previous studies showing that MS increases support

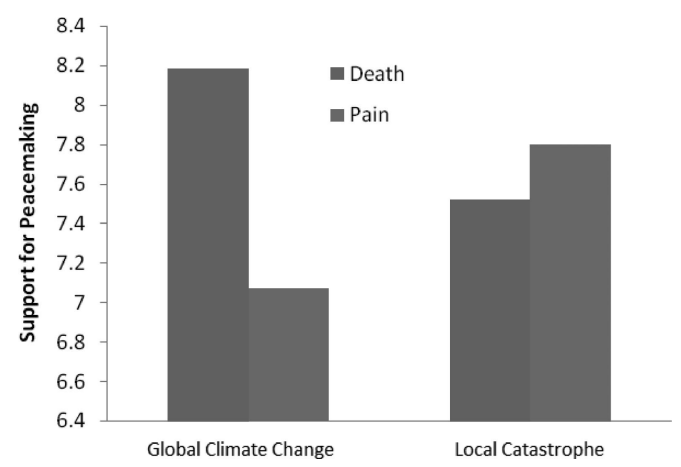

Figure 1. Support for diplomatic peace-building as a function of mortality salience (MS) and threat. for war and terrorism (e.g., Pyszczynski et al., 2006). One possible explanation is that whereas previous studies assessed support for war, the present study assessed attitudes toward structural peace-building, which has been shown to be a distinct construct (Vail \& Motyl, 2010). It may be easier and more socially acceptable to favor war than it is to disapprove of attempts at peace-making. It is also possible that whereas previous studies were focused on relatively specific conflicts, the present peace-building measure was more general and abstract.

\section{Study 2}

Study 2 was a conceptual replication of Study 1 with a measure of support for war against a specific country, Iran. If our explanations for the weak effect of MS observed in the control condition in Study 1 are correct, Study 2 should replicate previous research and show an MS induced increase in support for war, unless thoughts of global climate change were primed.

To enhance the generalizability of these studies, we employed different controls for the MS and global climate change manipulations in Study 2. Specifically, MS was compared with thoughts of uncertainty, which has been posited as an alternative to TMT in explaining why thoughts of death are threatening, (e.g., van den Bos, 2001). Instead of comparing thoughts of global climate change with thoughts of a localized catastrophe within one's own nation as in Study 1, thoughts of a catastrophe that affected an outgroup in a faraway place, flooding in China, were used as a control in Study 2. This enabled us to show that it was not the difference between catastrophic events in one's own country and the rest of the world that are responsible for the effects observed.

\section{Method}

Participants. Fifty-six psychology students (31 women, 25 men) at a Midwestern university in the United States participated, ranging in age from 18 to 22 years $(M=18.54$, $S D=.74)$. Participants received course credit in return for their participation.

Procedure. The study was conducted in groups of six participants. Participants completed a packet of questionnaires containing the manipulations and dependent measures. They were in- 
structed to work through the questionnaires in the order that they were presented and not look forward or backward in the packet. When they completed the questionnaires, participants were thoroughly debriefed and given course credit.

Materials. Participants completed the same global climate change task as in Study 1, with a control condition that asked them to imagine massive flooding in China and consequences such as: disturbed waterways, mass relocations, damaged towns and farm crops, and reconstruction (full text of this induction may be seen in the Appendix). Participants then completed the same MS manipulation as in Study 1, with parallel questions regarding thoughts of personal uncertainty as control condition, and then a word search puzzle as a distraction. This was followed by the dependent measure, a role-play measure of support for war against Iran, previously used by Rothschild (2008). Internal reliability was good, Cronbach's alpha $=.88$. Participants were asked to, "Imagine that you are Commander-in-Chief of the Armed Forces. It is your job to decide when to use your armed forces knowing that, as a result, some innocent civilians are likely to be killed." Participants responded to 11 sentence stems on a 10-point scale that began with "I would support using our armed forces against Iran . . . and included such completions as, "if Iran blatantly disregards the international community" or "if clear evidence indicated that Iran was developing a nuclear weapon." Thus, unlike Study 1, which assessed support for the general goal of peace building, Study 2 assessed support for military violence under specific circumstances against a specific country with which the United States has had a long-standing conflict that was receiving a great deal of recent attention in the national news at the time of the study.

\section{Results and Discussion}

A 2 (MS: Death vs. Uncertainty) $\times 2$ (Catastrophe: Global Climate Change vs. Flooding in China) ANOVA revealed a marginal main effect of Global Climate Change, $F(1,52)=3.55$, $p=.07, \eta^{2}=.06$, such that those in the climate change condition were lower in their support for war against Iran. As hypothesized, this effect was qualified by the MS $\times$ Global Climate Change interaction, $F(1,52)=5.00, p<.05$, $\eta^{2}=.09$ (Figure 2) ${ }^{2}$. Pairwise comparisons

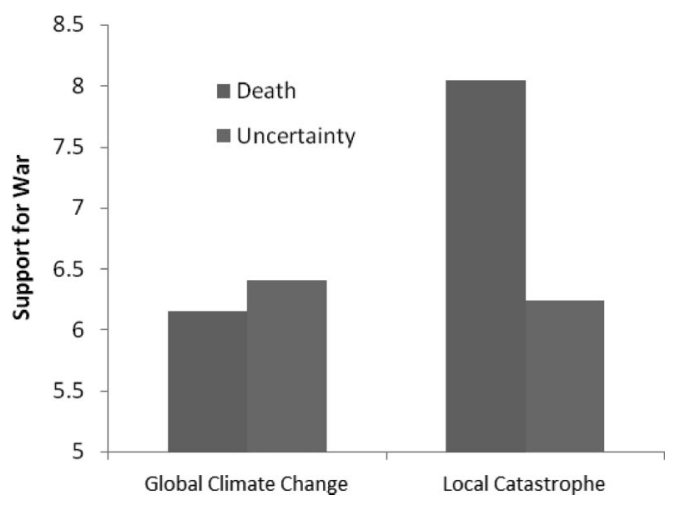

Figure 2. Support for war against Iran as a function of mortality salience (MS) and threat.

revealed that in the flooding in China control condition, participants reminded of mortality $(M=8.04, S D=1.24)$ were more supportive of war against Iran than those reminded of uncertainty $(M=6.24, S D=2.30), t(26)=-2.61$, $p<.05$. However, when asked to imagine the common catastrophe of global climate change, MS $(M=6.13, S D=1.45)$ did not significantly increase support for war compared with the uncertainty condition $(M=6.41, S D=1.63)$, $t(26)=0.47, n s$. Looked at differently, when confronted with personal uncertainty, participants who imagined either a localized or global catastrophe did not differ in their support for war against Iran, $t(28)=-.22, n s$. When reminded of mortality, however, imagining global climate change reduced support for war against Iran, $t(24)=3.61, p<.01$.

Study 2 conceptually replicated and extended the findings of Study 1. Whereas Study 1 showed that thoughts of global climate change channeled responses to MS toward general support for peace-building, Study 2 demonstrated the converse of this phenomenon, that focus on global climate change eliminated the effect of MS on increased support for military action against Iran. Because the two studies used different dependent measures and different controls for

\footnotetext{
${ }^{2}$ A 2 (male vs. female) $\times 2$ (MS vs. uncertainty) $\times 2$ (catastrophe: common vs. foreign) ANOVA revealed no main or interactive effects involving the sex variable on militarism against Iran $F \mathrm{~s}<.39, p(r e p) \mathrm{s}<.67$. Similar analyses were conducted in all three studies and because no gender-related effects were found, this variable was not included in the major analyses.
} 
the MS and climate change inductions, they provide converging evidence for the finding that thoughts of global climate change channel responses to existential threat away from violence and toward peace and reconciliation.

The finding that making the potential global consequences of climate change salient channels responses to existential fear toward more peaceful attitudes is encouraging, especially at a time when both of these threats loom as major international problems. However, the first two studies assessed this effect among American college students who are somewhat removed from the day-to-day effects of the conflicts toward which their attitudes were assessed. Would the peace-promoting effects of focusing on global climate change generalize to people more deeply enmeshed in an ongoing violent confrontation? Study 3 addressed this question.

\section{Study 3}

Study 3 examined whether the effect of priming thoughts of global climate change would extend to Muslim Palestinian citizens of Israel during the height of the 2009 Israeli invasion of Gaza. These people typically experience conflicted dual Israeli-Palestinian identity (Shamir \& Shikaki, 2002), but at times of escalating conflict between Israel and Arabs, they tend to identify more with their Palestinian brethren (Al-Haj, 1997; Jamal, 2004). Surveys showed that they were strongly opposed to the Israeli incursion into Gaza (Yaar \& Hermann, 2008).

To clarify for whom thoughts about global climate change produce the predicted effect, we assessed the role of individual differences in the tendency to perceive people as sharing a common humanity as a potential moderator of the effects. If thoughts of global climate change produce their peace-promoting effects because they lead people to see themselves as interdependent and sharing a common fate with others, this effect should be most pronounced among those prone to construe the world in such terms to begin with. Creating this sense of shared fate would be much more difficult among persons who typically avoid viewing their group and others in this light, which seemed a possible problem among our Palestinian sample at the time of this study when Israeli military presence was especially salient. Thus, we predicted a $\mathrm{MS} \times$ Global Climate Change $\times$ Common $\mathrm{Hu}-$ manity Orientation interaction on support for peaceful coexistence with Israeli Jews.

Study 3 also employed a different control condition for the global climate change manipulation, in an attempt to address a potential weakness of Studies 1 and 2. These studies had compared thoughts of the shared consequences of global climate change with a major catastrophic earthquake in San Francisco (Study 1) or catastrophic flooding in China (Study 2). One might argue that the relevance to the self of global climate change versus catastrophes occurring in faraway places was a confounding factor in these experiments. Hence, in Study 3 we used a control scenario (i.e., "major catastrophic earthquake in Israel") that was comparably self-relevant to the global climate change scenario.

\section{Method}

Participants. One hundred Muslim Palestinian citizens of Israel (54 women, 46 men), ranging in age from 18 to 25 years (median $=20$ ) volunteered to participate in the study. Participants were students at various colleges and universities in Israel. The study was conducted in January 2009, during the Israeli invasion of Gaza.

Materials and procedure. All materials were administered in Arabic by a Muslim Arab research assistant. Participants first completed the same global climate change induction as in previous studies. This time, the localized catastrophe control condition entailed imagining an earthquake in Israel and commenting on consequences such as: disturbing Israeli waters; forcing Israeli citizens to relocate; damaging Israeli towns; damaging crops; and reconstruction efforts.

Participants then completed the same MS manipulation with the open-ended questions as in Studies 1 and 2, with dental pain as the control condition. The dependent variable was a 13-item questionnaire (Cronbach's alpha $=.88$ ) assessing support for peaceful coexistence and reconciliation with Israeli Jews. Participants responded on a 7-point scale to items such as, "As difficult as it is, we need to find a way to live in peace with the Jews," and "I cannot forgive the Jews for their actions" (reversed).

Participants then completed filler questionnaires on leisure activity to create a delay between the manipulation and the measure of per- 
ceived common humanity (PCH; Motyl \& Vail, 2009). The PCH scale measures the perception that all people share an interconnected, uniquely human predicament. The 11 items on the $\mathrm{PCH}$ (Cronbach's alpha $=.78$ ) were responded to on a 6-point scale and included statements such as, "All people are linked to each other in a shared human bond," and "When one member of a community suffers, the whole community suffers." We administered this measure at the end rather than beginning of the session to avoid the possibility that completing it would activate concepts relevant to the dependent measure. Scores on the PCH measure were not affected by the other independent variables, legitimizing its use as a predictor variable in subsequent analyses. Finally, participants answered demographic questions and were debriefed.

\section{Results and Discussion}

Hierarchical regression analyses were conducted to assess the effects of MS, global climate change priming, and $\mathrm{PCH}$ on support for peace and reconciliation. ${ }^{3}$ We entered the effect coded $(-1,1)$ MS and global climate change variables, and standardized $\mathrm{PCH}$ scores (Step 1), all two-way interactions (Step 2 ), and the three-way interaction (Step 3). The analysis revealed a main effect of $\mathrm{PCH}, \beta=$ $.54, t(96)=6.28, p<.01$, and a significant three-way interaction, $\beta=.20, t(92)=2.23$, $p<.05$. Consistent with predictions, among participants high in $\mathrm{PCH}(+1 S D)$, MS significantly increased support for peace and reconciliation in the global climate change condition, $\beta=-.43, t(92)=-2.29, p<.05$, but had no effect in the local catastrophe condition, $\beta=-.02, t(92)=-.11, n s$. However, among participants low in $\mathrm{PCH}(-1 S D)$, MS marginally reduced support for peace and reconciliation in the global climate change condition, $\beta=$ $.30, t(92)=1.62, p=.07$, but had no significant effect in the local catastrophe condition, $\beta=-.09, t(92)=-0.57, n s$. The data for these effects on the original 7-point scale are presented in Figure 3.

To our knowledge, Study 3 was the first research to document the effect of MS on attitudes related to the Middle Eastern conflict among Palestinians. The results indicate that among Palestinian citizens of Israel who are low in perceptions of common humanity, MS and

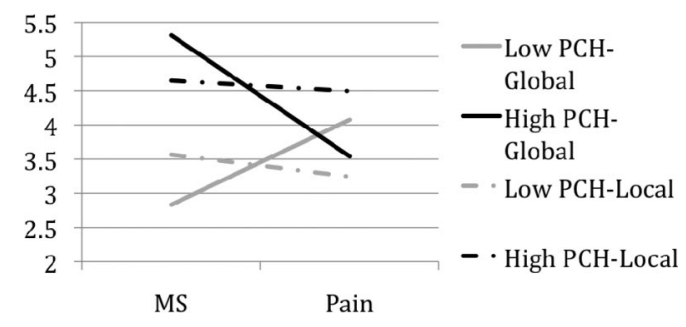

Figure 3. Support for peaceful coexistence with Israel as a function of mortality salience (MS), threat, and perception of common humanity.

thoughts of global climate change led to a marginal decrease in support for peace with Israeli Jews. This is consistent with previous studies showing that MS often increases support for violent solutions to this conflict (e.g., Hirschberger \& Ein-Dor, 2006). Given that these low PCH participants tend not see themselves as being part of a shared humanity, it makes sense that this decrease in support for peaceful solutions emerged in the global climate change condition. As Anderson and DeLisi (2011) suggested, global climate change is likely to pit groups against each other in pursuit of scarce resources, especially groups with long-standing animosities like the Palestinians and Israelis. However, consistent with our hypothesis and the results of Studies 1 and 2, participants high in $\mathrm{PCH}$ responded to $\mathrm{MS}$, when reminded of global climate change, with greater support for peaceful coexistence with Israeli Jews.

There were no significant effects of MS for either group in the local catastrophe condition. This might reflect the fact that, unlike Studies 1 and 2 , in which the localized catastrophes involved events that would not affect them, an earthquake in Israel would likely directly affect participants themselves, along with most others in the region, both Muslim and Jewish. Thus,

\footnotetext{
${ }^{3}$ The MS manipulation did not exert a significant effect on PCH, $\beta=-.12, t(96)=-1.12, p=.24$. Nor did the global climate change condition, $\beta=-.04, t(96)=-.36$, $p=.72$. Similarly, there was no significant interaction between the MS condition and global climate change condition, $\beta=.12, t(93)=-.74, p=.46$, between the MS condition and support for peace, $\beta=.103, t(93)=.92, p=$ .36 , and between global climate change condition and support for peace on $\mathrm{PCH}, \beta=-.107, t(93)=-.83, p=.41$. No significant three-way MS Condition $\times$ Global Climate Change Condition $\times$ Support for Peace Interaction was observed on PCH either, $\beta=.12, t(92)=.67, p=.5$.
} 
although this control condition did not entail a common global fate, it did depict a local disaster that would be shared by both sides of the conflict.

\section{General Discussion}

These studies demonstrate that increased awareness of the shared threat of global climate change can, at least under some circumstances, reduce support for war and promote efforts at peaceful coexistence and international cooperation. In Study 1, imagining the shared consequences of global climate change led Americans to respond to MS with increased support for structural peace-building and international diplomacy with respect to international conflicts. Study 2 replicated this effect on attitudes toward a specific conflict: Focus on global climate change eliminated the increase in support for war with Iran that MS otherwise produced among Americans. Study 3 found that even in the midst of an ongoing violent conflict, Palestinian citizens of Israel high in the tendency to construe humankind as interrelated responded to MS with increased support for peaceful coexistence with Israeli Jews when primed with thoughts of global climate change. These effects emerged across different controls for the effect of MS and thoughts of global climate change across the three studies.

These findings support the classic social psychological idea, as well as more recent conceptual refinements, that a superordinate threat can increase intergroup cooperation and reduce associated hostility (Allport, 1954; Gaertner et al., 1993; Sherif et al., 1961). The present studies extend previous work by showing that a shared global threat can eliminate the effect of death reminders-likely a frequent occurrence within the context of current geopolitical strife- on support for wars, and increase support for peaceful solutions to conflicts. Indeed, based on the current work, the threat of global climate change, which many believe to be the most serious of the many challenges humankind is currently facing (IPCC, 1996), might be precisely the sort of superordinate threat that Freud, Allport, and others envisioned as having the potential to bring warring peoples together. That this peace-promoting effect was found among Arab Israelis in the midst of the Israeli military incursion in Gaza suggests that the unifying effect of a potential global catastrophe can extend beyond the laboratory to very real conflicts at times when passions are running particularly high. Of course these findings should not be taken to imply that a shared threat will always be transformed into the shared goals of overcoming the threat. Indeed, death itself could be construed as a threat that all humans share, but research has shown that it can encourage people to both compete and cooperate. Understanding the conditions under which shared threats lead to cooperation should be an important goal for future research.

If thoughts of global climate change produced these effects because they instilled a sense that participants share a common fate with all humans, the effects should be especially prominent among persons who typically construe the social world in this way. This is precisely what Study 3 found. Among people low in common humanity orientation, MS tended to decrease support for peace when combined with thoughts of global climate change. It may be that a sense of shared fate is especially difficult to instill among persons low in common humanity orientation, especially during times of increased conflict, as was produced by the Israeli military action in Gaza during the time Study 3 was conducted. It also seems likely that people low in common humanity orientation would construe shared threats in zero-sum ways that lead to intergroup competition with respect to threatened resources. Yet for people high in the tendency to perceive a common bond with the rest of humanity, mortality thoughts combined with the global climate change threat led to increased desire for peaceful coexistence with the outgroup. This finding highlights the critical role that group categorization at the human-level can play in encouraging peaceful solutions to intergroup conflict, and is consistent with research showing, for example, that categorizing a historical perpetrator group at the maximally inclusive human level leads to greater reconciliatory efforts (Wohl \& Branscombe, 2005).

The current studies examined the effect of awareness of the potential future impact of global climate change rather than how people respond when in the midst of a shared global crisis. Whether such effects would occur once climate changes have already produced widely recognized catastrophic consequences is a dif- 
ferent question. It is possible and perhaps likely that, as Anderson and DeLisi (2011) suggest, the actual occurrence of such conflicts over resources would exacerbate hostilities and conflicts. This suggests that the time for increased focus on this potential future problem is now rather than after catastrophic consequences occur. Furthermore, global climate change is a contentious, politically and religiously charged issue, particularly in the United States. This divisive nature of the problem can be an impediment to achieving in the real world the peacepromoting effects we observed in our study. It should also be noted that our findings reflect an effect that occurred shortly after the priming induction; thus additional research is needed to address long-term effects of such thoughts on important behaviors such as voting or other forms of political action and practical ways these findings could be implemented to produce long-lasting and meaningful reductions in hostility in ongoing conflicts.

U.S. President Barack Obama's recent foreign policy statements have invoked the idea that the problems the world are facing, including global climate change, are too great to be solved by any one country and that solving them will require setting aside rivalry and conflict. In a speech about the problem of climate change, Obama stated:

This is also a global problem, so it's going to require a global coalition to solve it. If we've got problems with climate change ... that knows no boundaries; and the decisions of any nation will affect every nation... We are ready to engage - and we're asking other nations to join us in tackling this challenge together ... (Hass, 2009)

Obama's portrayal of the United States as seeking partnership with other countries to fight these global threats have led to a great deal of criticism and claims that such "displays of weakness" will embolden our enemies and make us less safe (Montopoli, 2009; Stolberg, 2009). The present findings suggest, however, that awareness of the potential for shared global catastrophe can reduce support for war and increase support for peace-making among at least some groups of people. To the extent that public opinion influences the behavior of leaders and nations, these findings suggest that keeping people mindful of shared global threats might facilitate a more peaceful world. They also suggest that increasing cooperation among groups currently embroiled in conflict should be added to potential financial benefits that are frequently discussed as beneficial side effects of addressing the serious problem of global climate change.

\section{References}

Al-Haj, M. (1997). Identity and orientation among Arabs in Israel: A state of a dual periphery. State, Government, and International Relations, 41-42, $103-122$.

Allport, G. W. (1954). The nature of prejudice. New York, NY: Addison-Wesley Publishing Company, Inc.

Anderson, C. A., \& Anderson, K. B. (1998). Temperature and aggression: Paradox, controversy, and a (fairly) clear picture. In R. Geen \& E. Donnerstein (Eds.), Human aggression: Theories, research, and implications for social policy (pp. 247-298). San Diego, CA: Academic Press.

Anderson, C. A., Anderson, K. B., Dorr, N., DeNeve, K. M., \& Flanagan, M. (2000). Temperature and aggression. In M. Zanna (Ed.), Advances in experimental social psychology, (Vol. 32, pp. 63-133). New York, NY: Academic Press.

Anderson, C. A., \& DeLisi, M. (2011). Implications of global climate change for violence in developed and developing countries. In J. Forgas, A. Kruglanski, \& K. Williams (Eds.), Social conflict and aggression (pp. 249-265). New York, NY: Psychology Press.

Ball, T. (2007). Global warming: The cold, hard facts. Retrieved from http://www.canadafreepress .com/2007/global-warming020507.htm

Canadian Meteorological and Oceanographic Society. (2002). Position statement on climate change. Retrieved from http://www.cmos.ca/climatec hangepole.html

Castano, E., \& Dechesne, M. (2005). On defeating death: Group reification and social identification as strategies for transcendence. In W. Stroebe \& M. Hewstone (Eds.), European review of social psychology (pp. 221-255). Chichester, England: Wiley.

Castano, E., Yzerbyt, V., Paladino, M., \& Sacchi, S. (2002). I belong, therefore, I exist: Ingroup identification, ingroup entitativity, and ingroup bias. Personality and Social Psychology Bulletin, 28, 135-143. doi:10.1177/0146167202282001

Christie, D. J., Tint, B. S., Wagner, R. V., \& Winter, D. D. (2008). Peace psychology for a peaceful world. American Psychologist, 63, 540-552. doi: 10.1037/0003-066X.63.6.540

Darley, J., \& Morris, W. N. (1975). Effects of stress and commonality of fate on helping behavior. 
Journal of Personality and Social Psychology, 31, 145-149. doi:10.1037/h0076236

Flippen, A., Hornstein, H., Siegal, W., \& Weitzman, E. (1996). A comparison of similarity and interdependence as triggers for in-group formation. Personality and Social Psychology Bulletin, 22, 882-893. doi:10.1177/0146167296229003

Freud, S. (1927). The future of an illusion. New York, NY: W. W. Norton \& Company.

Gaertner, S. L., \& Dovidio, J. F. (2000). Reducing intergroup bias: The common ingroup identity model. New York, NY: Psychology Press.

Gaertner, S., Dovidio, J., Anastasio, P. A., Bachman, B. A., \& Rust, M. C. (1993). The common ingroup identity model: Recategorization and the reduction of intergroup bias. In W. Stroebe \& M. Hewstone (Eds.), The European Review of Social Psychology (Vol. 4, pp. 1-26). New York: John Wiley and Sons.

Gaertner, S., Dovidio, J., Rust, M. C., Nier, J., Banker, B., Ward, C. M., . . Houlette, M. (1999). Reducing intergroup bias: Elements of intergroup cooperation. Journal of Personality and Social Psychology, 76, 388-402. doi:10.1037/0022-3514 .76.3.388

Gaertner, S., Mann, J. A., Murrell, A. J., \& Dovidio, J. (1989). Reduction of intergroup bias: The benefits of recategorization. Journal of Personality and Social Psychology, 57, 239-249. doi:10.1037/ 0022-3514.57.2.239

Greenberg, J., Pyszczynski, T., \& Solomon, S. (1986). The causes and consequences of a need for self-esteem: A terror management theory. In R. F. Baumeister (Ed.), Public self and private self (pp. 189-192). New York, NY: Berlin: SpringerVerlag. doi:10.1007/978-1-4613-9564-5_10

Greenberg, J., Pyszczynski, T., Solomon, S., Rosenblatt, A., Veeder, M., Kirkland, S., \& Lyon, D. (1990). Evidence for terror management theory II: The effects of mortality salience on reaction to those who threaten or bolster the cultural worldview. Journal of Personality and Social Psychology, 58, 308318. doi:10.1037/0022-3514.58.2.308

Greenberg, J., Simon, L., Pyszczynski, T., Solomon, S., \& Chatel, D. (1992). Terror management and tolerance: Does mortality salience always intensify negative reactions to others who threaten one's worldview? Journal of Personality and Social Psychology, 63, 212-220. doi:10.1037/0022-3514.63.2.212

Hass, C. (2009). President Obama in Iowa: "A choice between prosperity and decline." Retrieved from my.barackobama.com/page/community/post/ obamaforamerica/gGxckX

Hileman, B. (1999, August 9). Case grows for climate change. Chemical \& Engineering News, pp. 16-23. doi: 10.1021/cen-v077n032.p016

Hirschberger, G., \& Ein-Dor, T. (2006). Defenders of a lost cause: Terror management and violent resistance to the disengagement plan. Personality and Social Psychology Bulletin, 32, 761-769. doi:10.1177/0146167206286628

Hirschberger, G., Pyszczynski, T., \& Ein-Dor, T. (2009). Vulnerability and vigilance: Threat awareness and perceived adversary intent moderate the impact of mortality salience on intergroup violence. Personality and Social Psychology Bulletin, 35, 597-607. doi:10.1177/0146167208331093

Houlette, M. A., Gaertner, S. L., Johnson, K. M., Banker, B. S., Riek, B. M., \& Dovidio, J. F. (2004). Developing a more inclusive social identity: An elementary school intervention. Journal of Social Issues, 60, 35-55. doi:10.1111/j.0022-4537 .2004.00098.x

Intergovernmental Panel on Climate Change (IPCC). (1996). Climate change 1995: The science of climate change. New York, NY: Cambridge University Press.

Jamal, A. (2004). Between homeland, nation, and state: Patriotism among the Palestinian minority in Israel. In A. Ben-Amos, \& D. Bar-Tal (Eds.), Patriotism: Ahavat Hamoledet [Patriotism: Homeland love] (pp. 399-453). Tel Aviv, Israel: Hakibbutz Hameuhad [Hebrew].

Joint Science Academies. (2005). Joint science academies' statement: Global response to climate change. Retrieved from http://nationalacade mies.org/onpi/06072005.pdf

Jonas, E., Martens, A., Niesta, D., Fritsche, I., Sullivan, D., \& Greenberg, J. (2008). Focus theory of normative conduct and terror management theory: The interactive impact of mortality salience and norm salience on social judgment. Journal of Personality and Social Psychology, 95, 1239-1251. doi:10.1037/a0013593

Kesebir, P., \& Pyszczynski, T. (2011). A moralexistential account of the psychological factors fostering intergroup conflict. Social and Personality Psychology Compass, 5, 878-890. doi:10.1111/j.1751-9004.2011.00397.x

Kesebir, P., \& Pyszczynski, T. (2012). The role of death in life: Existential aspects of human motivation. In R. Ryan (Ed.), The Oxford handbook of human motivation (pp. 43-64). New York, NY: Oxford University Press.

McGregor, H. A., Lieberman, J. D., Greenberg, J., Solomon, S., Arndt, J., Simon, L., \& Pyszczynski, T. (1998). Terror management and aggression: Evidence that mortality salience motivates worldview-threatening others. Journal of Personality and Social Psychology, 74, 590-605. doi:10.1037/ 0022-3514.74.3.590

Montopoli, B. (2009). Cheney hits Obama hard, tradition be damned. Retrieved from http://www .cbsnews.com/blogs/2009/04/24/politics/political hotsheet/entry4966740.shtml 
Mottola, G. R., Bachman, B. A., Gaertner, S. L., \& Dovidio, J. F. (1997). How groups merge: The effects of merger integration patterns on anticipated commitment to the merged organization. Journal of Applied Social Psychology, 27, 13351358. doi:10.1111/j.1559-1816.1997.tb01809.x

Motyl, M., Hart, J., \& Pyszczynski, T. (2010). When animals attack: The effects of mortality salience, infrahumanization of violence, and authoritarianism on support for war. Journal of Experimental Social Psychology, 46, 200-203. doi:10.1016/j .jesp.2009.08.012

Motyl, M., Vail, K., \& Pyszczynski, T. (2009). Waging terror: Psychological motivations in cultural violence and peacemaking. In M. Morgan (Ed.), The day that changed everything? The impact of 9-11 (pp. 2336). New York, NY: Greenwood-Praeger.

Motyl, M. S., \& Vail, K. E., III. (2009). The Ubuntu scale: A measure of the perception of a common humanity. Unpublished manuscript. University of Colorado at Colorado Springs.

Nier, J. A., Gaertner, S. L., Dovidio, J. F., Banker, G. S., Ward, C. M., \& Rust, M. C. (2001). Changing interracial evaluations and behavior: The effect of common group identity. Group Processes and Intergroup Relations, 4, 299-316. doi:10.1177/ 1368430201004004001

Pyszczynski, T., Abdollahi, A., Solomon, S., Greenberg, J., Cohen, F., \& Weise, D. (2006). Mortality salience, martyrdom, and military might: The Great Satan versus the Axis of Evil. Personality and Social Psychology Bulletin, 32, 525-537. doi: 10.1177/0146167205282157

Pyszczynski, T., Greenberg, J., \& Solomon, S. (1999). A dual process model of defense against conscious and unconscious death-related thoughts. An extension of terror management theory. Psychological Review, 106, 835-845. doi:10.1037/ 0033-295X.106.4.835

Pyszczynski, T., Solomon, S., \& Greenberg, J. (2003). In the wake of 9/11: The psychology of terror. Washington, DC: American Psychological Association. doi:10.1037/10478-000

Rothschild, Z. K. (2008). More human but less humane: The effect of mortality salience and perceived similarity on infra-humanization and support for violence against out-groups. Unpublished master's thesis. University of Colorado at Colorado Springs.

Rothschild, Z., Abdollahi, A., \& Pyszczynski, T. (2009). Does peace have a prayer? The effect of mortality salience, compassionate values and religious fundamentalism on hostility toward out- groups. Journal of Experimental Social Psychology, 45, 816-827. doi:10.1016/j.jesp.2009.05.016

Schneider, D. (1997, March). The rising seas. Scientific American, 276, 112-117. doi: 10.1038/ scientificamerican0397-112

Shamir, J., \& Shikaki, K. (2002). Self-serving perceptions of terrorism among Israelis and Palestinians. Political Psychology, 23, 537-557. doi:10 .1111/0162-895X.00297

Sherif, M. (1966). In common predicament: Social psychology of intergroup conflict and cooperation. New York, NY: Houghton Mifflin.

Sherif, M., Harvey, O. J., White, B. J., Hood, W. R., \& Sherif, C. W. (1961). Intergroup conflict and cooperation: The Robbers Cave experiment. Norman: University of Oklahoma Book Exchange.

Stolberg, S. G. (2009). Unemployed, unapologetic, and unrestrained: It's Cheney unbound. Retrieved from http://www.nytimes.com/2009/04/24/us/ 24cheney.html?em

Vail, K. E., III, \& Motyl, M. S. (2010). Support for diplomacy: Peacemaking and militarism as a unidimensional correlate of social, environmental, and political attitudes. Peace and Conflict: Journal of Peace Psychology, 16, 29-57. doi:10.1080/ 10781910903486813

van den Bos, K. (2001). Uncertainty management: The influence of uncertainty salience on reactions to perceived procedural fairness. Journal of Personality and Social Psychology, 80, 931-941. doi: 10.1037/0022-3514.80.6.931

Weise, D. R., Pyszczynski, T., Cox, C., Arndt, J., Greenberg, J., Solomon, S., \& Kosloff, S. (2008). Interpersonal politics: The role of terror management and attachment processes in shaping political preferences. Psychological Science, 19, 448-455. doi:10.1111/j.1467-9280.2008.02108.x

Wohl, M. J. A., \& Branscombe, N. R. (2005). Forgiveness and collective guilt assignment to historical perpetrator groups depend on level of social category inclusiveness. Journal of Personality and Social Psychology, 88, 288-303. doi:10.1037/ 0022-3514.88.2.288

Yaar, E., \& Hermann, T. (December, 2008). The War and Peace Index. Tel Aviv, Israel: The Tami Steinmetz Center for Peace Research, Tel-Aviv University.

Zhang, D. D., Brecke, P., Lee, H. F., He, Y. Q., Zhang, J. (2007). Global climate change, war, and population decline in recent human history. PNAS Proceedings of the National Academy of Sciences of the United States of America, 104, 1921419219. doi:10.1073/pnas.0703073104 


\section{Appendix}

\section{Climate Prime Manipulation Materials}

\section{Climate Change Imagery Task: Studies 1-3}

This assessment is a recently developed, innovative measure of personality. Recent research suggests that the ability to imagine future events tells us a considerable amount about individuals' personality. Your response to this survey will be content-analyzed in order to assess certain dimensions of your personality. Your honest response to the following question will be appreciated.

1. There are differing viewpoints on global climate change these days. Most scientists agree that it is occurring or will occur, but nobody can predict the future. Regardless of whether global climate change is real and happening, or will happen sometime in the future, think about what it would be like IF it did happen.

For this task, set aside your personal and scientific views towards global climate change and think about what would happen IF global climate change were to occur. The following list contains some of the physical results of climate change that most scientists suggest are likely. List and describe some of the consequences global climate change would have on people living around the planet. Specifically, we are interested in the scenarios for how individual people, governments, and other groups might react if the following events that scientists say are likely to happen do actually happen.

a. If polar ice caps melted and sea levels rose:

b. If people are forced to move from their rural homes to more urban areas:

c. If rising water temperatures caused more severe storms:

d. If farmers experienced longer drought seasons:

e. If more jobs were created around the world by pursuing new, clean energy sources:

\section{San Francisco Earthquake Control Imagery Task: Study 1}

This assessment is a recently developed, innovative measure of personality. Recent research suggests that the ability to imagine future events tells us a considerable amount about individuals' personality. Your response to this survey will be content-analyzed in order to assess certain dimensions of your personality. Your honest response to the following question will be appreciated.

1. There are differing viewpoints on the likelihood of a massive earthquake in San Francisco (a.k.a. "the Big One") these days. Most scientists agree that it will occur at some point, but nobody can predict the future. Regardless of whether a massive earthquake in San Francisco is a real risk and will happen think about what it would be like IF it did happen.

For this task, set aside your personal and scientific views towards a massive earthquake occurring in San Francisco and think about what would happen IF "The Big One" were to occur. The following list contains some of the physical results of a major urban earthquake that most scientists suggest are likely. List and describe some of the consequences the massive earthquake would have on human beings living in San Francisco. Specifically, we are interested in the scenarios for how individual people, governments, and other groups might react if the following events that scientists say are likely to happen do actually happen.

a. If the earthquake disturbed the waters in San Francisco bay:

b. If people are forced to move from San Francisco to other areas:

c. If the earthquake caused severe aftershocks:

d. If the grape farms were damaged and could not produce crops: 
e. If more construction jobs were created in San Francisco to repair the damage:

\section{China Flood Control Imagery Task: Study 2}

This assessment is a recently developed, innovative measure of personality. Recent research suggests that the ability to imagine future events tells us a considerable amount about individuals' personality. Your response to this survey will be content-analyzed in order to assess certain dimensions of your personality. Your honest response to the following question will be appreciated.

1 . There are differing viewpoints on the massive flooding in China these days. Most scientists agree that it will occur again at some point, but nobody can predict the future. Regardless of whether massive flooding in China is a real risk and will happen again soon, think about what it would be like IF it did happen again.

For this task, set aside your personal and scientific views towards massive flooding occurring in China and think about what would happen IF it were to occur again. The following list contains some of the physical results of a major flood that most scientists suggest are likely. List and describe some of the consequences the massive flooding would have on people living in China. Specifically, we are interested in the scenarios for how individual people, governments, and other groups might react if the following events that scientists say are likely to happen do actually happen.

a. If the flooding disturbed their waterways:

b. If people are forced to move from China to other areas:

c. If the flooding caused severe damage to their towns:

d. If their farms were damaged and could not produce crops:

e. If more construction jobs were created in China to repair the damage:

\section{Imagery Task: Israel Earthquake Control Study 3}

This assessment is a recently developed, innovative measure of personality. Recent research suggests that the ability to imagine future events tells us a considerable amount about individuals' personality. Your response to this survey will be content-analyzed in order to assess certain dimensions of your personality. Your honest response to the following question will be appreciated.

1. There are differing viewpoints on a major earthquake in Israel. Most scientists agree that it will occur again at some point, but nobody can predict the future. Regardless of whether a major earthquake is a real risk and will happen again soon, think about what it would be like IF it did happen again.

For this task, set aside your personal and scientific views towards a major earthquake in Israel and think about what would happen IF it were to occur again. The following list contains some of the physical results of a major earthquake that most scientists suggest are likely. List and describe some of the consequences a massive earthquake would have on people living in Israel. Specifically, we are interested in the scenarios for how individual people, governments, and other groups might react if the following events that scientists say are likely to happen do actually happen.

a. If the earthquake disturbed the water supply:

b. If people are forced to move from Israel to other areas:

c. If the earthquake caused severe damage to towns in this region:

d. If farms were damaged and could not produce crops:

e. If more construction jobs were created in Israel to repair the damage: 